\title{
Numerical Design and Performance Analysis of a Tug Boat Propulsion System
}

\author{
Samson Nitonye, Sidum Adumene, Ukpokpo Umorami Howells \\ Department of Marine Engineering, Rivers State University, Port Harcourt, Nigeria \\ Email: nitonye.samson@ust.edu.ng
}

How to cite this paper: Nitonye, S., Adumene, S. and Howells, U.U. (2017) Numerical Design and Performance Analysis of a Tug Boat Propulsion System. Journal of Power and Energy Engineering, 5, 80-98. https://doi.org/10.4236/jpee.2017.511007

Received: October 20, 2017

Accepted: November 27, 2017

Published: November 30, 2017

Copyright $\odot 2017$ by authors and Scientific Research Publishing Inc. This work is licensed under the Creative Commons Attribution International License (CC BY 4.0).

http://creativecommons.org/licenses/by/4.0/

(c) (i) Open Access

\begin{abstract}
The aim of this project is to design and analyze the propulsion system for a tugboat for optimum performance. In so doing, certain approved procedures were followed; these procedures included getting the desired tugboat dimension, using ITTC methods, Gertlers charts, Bp charts etc. to estimate the bare hull resistance of the tugboat, estimating the effective power that must be employed to overcome this tug resistance. Numerical software code was developed to determine the various performance indicators of the propulsion system. The effective power was used as a basis for selecting the main engine and designing of a suitable propeller capable of propelling the tugboat for the various sea state were evaluated. Propeller cavitation was also put into consideration during this design. Hence in matching the engine to the propeller a series of calculations were done across a speed range of $300-500 \mathrm{rpm}$ in other to effectively ascertain the engine-propeller matching point. The result shows that the point of engine-propeller matching is at $335 \mathrm{rpm}$ and $2550 \mathrm{KW}$ respectively. This provides a guide for the selection of a main engine with an acceptable sea service margins. All designs were done in accordance to classification organization and regulations.
\end{abstract}

\section{Keywords}

Tugboat, Propulsion System, Engines, Resistance, Effective Power, Speed

\section{Introduction}

The word Propulsion originated from the Latin words pro, which means before or forward, and pellere, which means to drive. Propulsion systems comprise of all the components used in generating power, transmitting these power to the propeller via a shaft and reduction gear (as shown in Figure 1 and Figure 2), which in turn converts this power to thrust used in moving a vessel forward. 


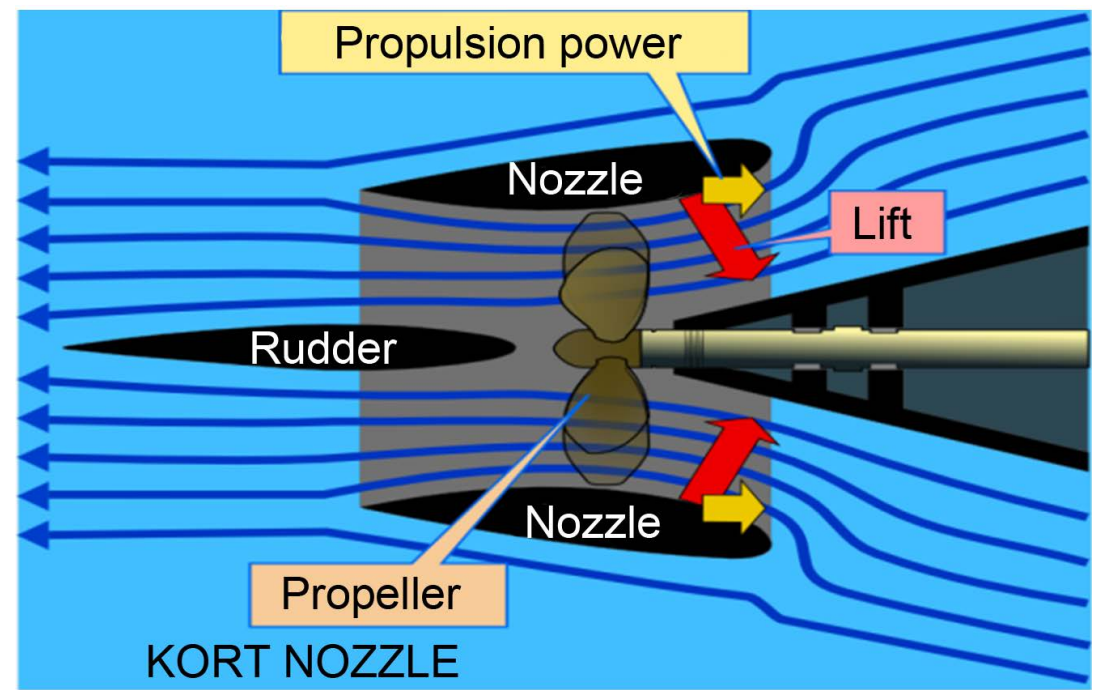

Figure 1. Propeller-Nozzle arrangement [5].

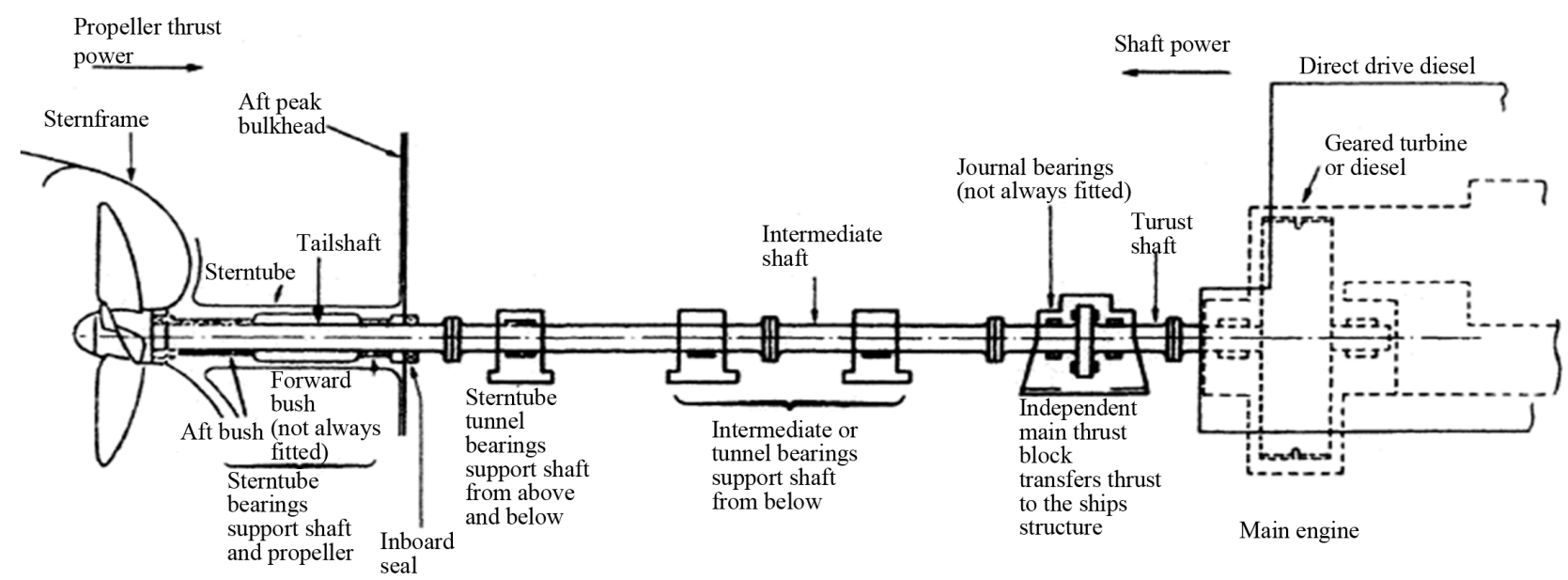

Figure 2. Propeller Shaft arrangement [6].

Ship propulsion is not only restricted to just moving vessel forward against forces such as air drag, friction, towing resistance etc., but is also responsible for stopping, maneuvering of the vessel and keeping it in a static position against water current when required [1]. A tug boat is a small but very powerful vessel used in towing (pulling) or tugging bigger vessels that cannot move by themselves or are not self-propelled like some barges. Tug boats can also be used as fire fighters, ice breakers etc. the strength of a tug boat and its ability to maneuver effectively depends solely on the propulsion system installed [2]. There are different types of propulsion system for marine operation. Diesel electric propulsion system is one of the propulsion that has configuration that is fitted with the bow and aft thrusters, and is often mounted with one up to eight azimuth thrusters. The bow and aft thrusters are electrically driven [3]. All though the impacts of these ships on the whole maritime industry is most times been neglected, but their value is mostly felt in maneuvering during bad weather con- 
ditions and during vessel breakdown etc. The importance of tugboat cannot be overemphasized in a region like the Niger Delta with vast coastal lines [4].

The effectiveness of a tug boat is characterized by its ability to tow and maneuver easily, which is a major concern in the marine industry. Most important factor is propulsive design is the interaction between the propeller and the nozzle with the hull [5]. This research will seek for ways of solving that problem. It is also believed that this research work will be significant in terms of designing tugboats with low fuel consumption and operating cost.

\subsection{Propulsion Systems and Design Parameters for Tugboats}

Robert Wilson invented the screw propeller "after watching a soldier demonstrate on how paddle wheels could move a boat faster than oars, but in rough seas the paddle wheels became less effective was perplexed, again on seeing a windmill in operation made him wonder if a design like the blades of a windmill could be used to drive a boat". By the time he left school at age nine, he had devised a model boat, which was propelled by rotating skulls. The forerunner of the screw propeller. Wilson later constructed a model boat and experimented with different numbers and designs of blades. He varied the blade's area and pitch, always comparing them with his model paddle wheels [7].

According to the society of Naval Architects and Marine Engineers "The design of a marine propeller is almost invariably carried out by one or two methods. Although each method covers a number of procedures differing in details. In the first one, the design is based upon charts giving the results of open water efficiencies on a series of model propellers. These cover variations in a number of the design parameters such as pitch ratio, blade area, number of blades and section shapes: A propeller which conforms to the characteristics of any particulars series can be rapidly designed and drawn to such the required ship condition. The second method involves a loaded propeller prone to cavitation, or has to work in a very uneven wake pattern, when it is desirable to carry out a detailed design using circulation theory, they further stated that, this involves finding the chord width, section shape, pitch and efficiency at a number of radii to suit the average circumferential wake values and give optimum efficiency and protect cavitation [8].

\subsection{Different Vessels and Their Propulsion Systems}

\subsubsection{Propulsion Systems for Naval Vessels (Warship)}

Naval vessels and other types of military vessels with major priorities being speed and maneuverability and not necessarily fuel efficiency, have high powered propulsion systems. Their enormous propulsion power comes mainly from high fuel thirsty gas turbines and steam turbines (COGAS). The US navy is an avid consumer of steam plants, a great number of their vessels obtain steam form nuclear means. In these vessels steam plants powered by nuclear reactors are used as the prime movers for turning the propellers of these vessels. Most propulsion system set up for naval vessels are one gas turbine for naval or mili- 
tary operations and the diesel engines for cruising. Each is capable of delivering power to a controllable pitch propeller [9].

\subsubsection{Propulsion Systems for Ferries (Double Ender)}

The double ender ferry is another vessel with a unique propulsion system. It has an interesting design; one propeller and rudder at one end of the vessel. They are usually equipped with diesel engines to produce power. They are all coupled to a gear box by two air operated clutches. The shafts are quite long since they run through both ends of the vessel via the centerline; and are clutched as well, to allow both engines to drive one shafts or both with controllable pitch propellers, and two rudders, these types of vessels are very responsive with a service speed that is relatively high. These vessels are used for transporting large quantities of vehicles and passengers on short runs in calm waters [10].

\subsubsection{Propulsion Systems for Icebreakers Vessels}

Ice breakers are vessels used for icebreaking in deep waters, the pacific and Atlantic oceans. They require large horse power for their propulsion systems due to the work they perform. Icebreakers usually encounter shock loading from hitting big piece of ice; as such diesel engines were not really ideal as their prime movers. Hence, the diesel electric propulsion system allows these shocks to be filtered by the electrical machinery. The propulsion systems for icebreakers consist of medium speed engines, alternating current (AC) generators, and electrical motors driving two fixed pitch propellers. Fixed pitch propellers are used because they are more durable and less likely to fail during ice breaking [11].

\subsubsection{Propulsion System for a Cruise Ship}

Cruise ships are mostly leisure vessels with large hotel loads and power requirements. They are built for high degree of reliability with efficient systems with modern technology systems. Their propulsion systems are usually diesel-electric driven. The engines are mostly four-stroke medium speed engines due to their bigger size to power ratio. The propulsion system is made up of electrical motors which are built into pods controlled by cyclo-converters. The pods hang below the ship hull increasing their efficiency. Some cruise ships are installed with up to nine or ten identical medium speed diesel engines. All these engines supply a common electrical bus and the power needed for propulsion is simply tapped from the bus and delivered to the propellers [12].

\subsubsection{Propulsion Systems for Special or Research Vessels}

The propulsion systems for specialized vessels and research vessels has the common arrangement of four sized medium speed four-stroke engines, two engines each are connected to a common shaft with a single propeller. The four engines with and two shafts with controllable pitch propellers (CPP) provides a high degree of redundancy and versatility. Having two engines connected to one shaft offers a great level of redundancy. They can be operated simultaneously or individually by means of the clutch. The gear box is there to compensate for the 
high speed of the engines and allow the propeller to turn at a more efficient slower speed. The controllable pitch propellers basically provide these vessels with great maneuverability and the quick response they require [13].

\subsubsection{Propulsion System for LNG Vessels}

LNG vessels with a boiling point of $-161.5^{\circ} \mathrm{C}$ at atmospheric pressure, is highly volatile and thus demands a containment system that can maintain a temperature near or below its boiling point. However, a certain percentage of vapors called boil off gas that accumulate will increase the tank pressures. This increase in pressure if not released could lead to explosions. To solve this problem, the boil off gas is piped into the engine room for propulsion purpose. The propulsion system for LNG consist of using boil off gases as fuels in boilers and the high pressure from steam turbines is used for propulsion. In recent times boil off gas are been adapted for use in diesel engines. Boil of gasses are also used for power generation and an electric motor is then connected to the propeller for propulsion [14].

\subsubsection{Propulsion System for Tugboats}

The power of a tug boat depends entirely on the propulsion system installed. Today the primary source of propeller power especially for tug boats is the diesel engine, the power required and rate of propeller revolution however depends on the shape and size of the tug hull and the design of the propeller. The term power is used in the identification of marine diesel engines and internal combustion engines in which the word "power" is referring to indicated power $\left(P_{i}\right)$ and the brake power $\left(P_{b}\right)$ generated by the engine. Generally the power generated by the combustion process in the engine cylinder is transmitted by the mechanical movement of the crankshaft to move the ship propeller via the propeller shaft [15].

Tugboat engines produces power ranging from 500 - $2500 \mathrm{KW}$ (680 - 3400 HP). Since tugboats are designed to be highly maneuverable, different kinds of propulsion systems have been developed. Earlier tugboats used paddle wheels as their main propulsor, these days paddle wheels have been replaced with propellers such as the cycloid propeller, z-drive propeller, steer prop, etc. The propulsion system of a tug boat consist mainly of the prime mover (diesel engine) with a reduction gear attached, and a shaft line connecting the gear box to the propeller which provides the thrust for propelling the tugboat. We effectively design the propulsion system of a tug boat, and show clearly the relationship between the prime mover, reduction gear box, shaft and the propeller, and how they relate to the overall propulsion system of the tugboat, effectively select or design a suitable propeller for the prime mover etc [6] [16].

To enhance the working condition of the tug boat at full load and other sea conditions we must take a critical account of structural integrity and the stability of the vessel during any operation. [17] and [18]. In case of extreme and long-time operation of the vessel, advanced propulsion systems are most suitable 
to aid the maneuvering. It has been proven that the diesel electric propulsion show a less efficiency when compare with the diesel mechanical drive. Further observation revealed that the propulsive losses is higher in a diesel electric drive system that the diesel mechanicals [19] [20]. In most modern propulsion systems, research shows that a hybrid propulsion system proved to be more economically viable, especially in fuel consumption. To aid the performance of such complex configuration, computational control systems that monitor the system characteristic are installed [21]. Also for an effective yaw manoeuvres of the vessel, the thrusters are often grouped at the bow and stern of the vessels. The thrust output of the thrust is greatly influences by the propeller axis. Although, if the propeller axis coincides, the thrust is greatly reduced and therefore affect the advance coefficient of the propulsor [19] [21]. This work therefore present a design analysis of a mechanical drive tug boat propulsion system for extreme operating conditions and optimal performance.

\section{Materials and Methods}

\subsection{Research Methods}

The methodology used in this research is the analytical method, Mathematical and engineering formulas, graphs and charts were also used in the design of the propulsion system for the tug boat at the end of the design $\mathrm{C}^{++}$software was then used for result validation and iterations.

\subsubsection{Tug Resistance Estimation}

The estimation of the resistance of any vessel can be done by various methods which are ITTC method, ATTC method, Gertlers chart method, Guldhammer, Harwld method, Mumford's equations etc. however, for the purpose of this design only the ITTC method and Gertlers chart method will be considered because of their high power performance factor, the vessel tested by being broken down into separate pieces and other advantages [22]. We know every method has advantages and disadvantages concerning resistance estimation. Table 1 shows the design parameters for the tug boat and Table 2 shows the Model engine data.

Total tug resistance

$$
R_{T}=C_{T} \times \frac{1}{2} \times \rho_{w} \times S_{w} \times V_{s}^{2}
$$

But

$$
C_{T}=C_{F}+C_{R}+C_{A}
$$

Again,

$$
C_{F}=\frac{0.75}{\left(\log R_{e}-2\right)^{2}}
$$

$$
R_{e}=\frac{V_{s} \times L}{\gamma} \text { but, }
$$


Table 1. Design parameters for the tug boat [23].

\begin{tabular}{ccc}
\hline S/No & & \\
\hline 1 & Length between perpendiculars $\left(L_{P P}\right)$ & $42.12 \mathrm{~m}(138.19 \mathrm{ft})$ \\
2 & Length over all (LOA) & $45.72 \mathrm{~m}(150.0 \mathrm{ft})$ \\
3 & Design draft T(keel) & $5.73 \mathrm{~m}(18.8 \mathrm{ft})$, \\
4 & Moulded Breath $\left(M_{B}\right)$ & $10.05 \mathrm{~m}(33.0 \mathrm{ft})$, \\
5 & Moulded depth $\left(M_{D}\right)$ & $4.79 \mathrm{~m}(15.7 \mathrm{ft})$, \\
6 & Gross Tonnage & $279 \mathrm{Tonnes}$ \\
7 & Block Coefficient $\left(C_{B}\right)$ & 0.500 \\
\hline
\end{tabular}

Table 2. Model engine data [27].

\begin{tabular}{|c|c|c|c|c|c|c|c|c|c|c|}
\hline Model & Cycle & Cylinders & $\begin{array}{l}\text { Bore } \\
(\mathrm{mm})\end{array}$ & $\begin{array}{l}\text { Stroke } \\
(\mathrm{mm})\end{array}$ & $\begin{array}{c}\text { Mean } \\
\text { Piston speed }\end{array}$ & $\begin{array}{c}\text { Speed } \\
\text { (rev/min) }\end{array}$ & $\begin{array}{c}\text { Output } \\
\text { (kw/cyl) }\end{array}$ & $\begin{array}{c}\text { Out range } \\
(\mathrm{kw})\end{array}$ & $\begin{array}{c}\text { Bmep } \\
\text { (bar) }\end{array}$ & $\begin{array}{c}\text { Sfoc } \\
\text { (g/kwh) }\end{array}$ \\
\hline $320 \mathrm{NA}$ & 4 & $6 v$ & 114 & 127 & 10.2 & & & $153-262$ & 16.9 & $211-220$ \\
\hline $3208 \mathrm{TA}$ & 4 & $4 v$ & 114 & 127 & 10.1 & $2400-2800$ & 40.5 & $153-264$ & 16.9 & $213-245$ \\
\hline $3204 \mathrm{NA}$ & 4 & $6 \mathrm{v}$ & 114 & 127 & 10.1 & $2000-2200$ & 18.8 & $173-265$ & 16.9 & $213-246$ \\
\hline $3206 \mathrm{~T}$ & 4 & $6 v$ & 137 & 165 & 7.4 & $1800-2100$ & 67.2 & $153-270$ & 16.9 & $206-217$ \\
\hline 3406TA & 4 & $6 \mathrm{v}$ & 137 & 165 & 7.4 & $1200-1350$ & 38.5 & $153-271$ & 16.9 & 206-217 \\
\hline $3516 \mathrm{C}$ & 4 & $6 v$ & 114 & 784 & 9.2 & $1200-1800$ & 35 & $1230-2525$ & 16.9 & $206-222$ \\
\hline $3516 \mathrm{TA}$ & 4 & $16 \mathrm{v}$ & 170 & 190 & 7.2 & 1800 & 130.5 & 2088 & 16.1 & $200-208$ \\
\hline 3516TA & 4 & $12 \mathrm{v}$ & 170 & 190 & 8.2 & & 130.5 & $895-1242$ & 14.7 & $204-216$ \\
\hline
\end{tabular}

For maximum speed of hull

$$
\frac{V_{S}}{\sqrt{L_{p p}}}=1.34
$$

And $V_{s}=\sqrt{L_{p p}} \times 1.34$

Hence $R_{e}=1170709486 \times 10^{9}$ and $C_{F}=0.015011$

$C_{R}$ is gotten from Gertler's chart using Froude's number $F_{n}=\frac{V_{s}}{\sqrt{L g}}$,

$$
F_{n}=\frac{16 \times 0.514}{\sqrt{150} \times 9.81}
$$

But $C_{B}=\frac{\nabla}{L \times B \times L}$

At $C_{B}=0.500, \quad \nabla=0.500 \times 150 \times 33 \times 18.8$

Similarly, $\frac{\nabla}{L^{3}}=\frac{46530}{150^{3}}$

$$
\Rightarrow C_{T}=0.015011+0.64+0.004
$$

The ship's wetted surface area is calculated using Mumford's formula, 


$$
S=1.7 L_{p p} \times d+\frac{\nabla}{d} \mathrm{ft}^{2}
$$

Now substituting all the values into Equation (1), the value for $R_{T}$ can now be estimated.

\subsubsection{Estimating Force of the Tug}

The effective force needed to tow the tug at a given speed in smooth water is known as the resistance. This is given as $F_{T}=R_{T}$, and the power needed to overcome this resistance is the effective power $\left(P_{E}\right)$.

$$
\begin{gathered}
P_{E}=R_{T} \times V_{s} \quad[24] \\
\text { But } \eta_{D}=\frac{P_{E}}{P_{D}}
\end{gathered}
$$

And $P_{D}=\frac{P_{E}}{\eta_{D}}$

$$
\text { Similarly, } \eta_{S}=\frac{P_{D}}{P_{S}}
$$

For the purpose of this design the engines will be located aft, then $\eta_{S}=0.98$ or $98 \%$.

Again, the engine brake power $\left(P_{B}\right)$ is given by,

$$
\eta_{G}=\frac{P_{S}}{P_{B}}
$$

where $\eta_{G}$ is the efficiency of the gearing system to be used, and for this design a mechanical gearing system will be used hence,

$$
\eta_{G}=0.93 \text { or } 93 \%
$$

Engine speed $=1800 \mathrm{rpm}, \quad P_{I}=2525 \mathrm{~kW}$

Since the engine is a high speed one, a reduction gear will be used.

Let $N_{!}=$engine speed and $N_{2}=$ propeller speed and the gear ratio $I=4.5$.

$$
I=\frac{N_{!}}{N_{2}}
$$

Hence, $N_{2}=\frac{1800}{4.5}$.

\subsection{Propeller Design}

Preliminary calculated values for a twin screw propeller,

$$
\begin{gathered}
\text { 1) } W=0.55 C_{B}-0.20 \\
\text { 2) } t=\left(1.67-2.3 \frac{C_{B}}{C_{W L}}+1.5 C_{B}\right) \times w \quad[24] \\
\text { But } C_{W L}=C_{B}+0.10 \\
\text { 3) } V_{a}=(1-w) \times V_{s}
\end{gathered}
$$

4) Hull Efficiency of the Tug $\eta_{H}$ 


$$
\begin{gathered}
\eta_{H}=\frac{P_{E}}{P_{D}}=\frac{R_{T} \times V_{s}}{T \times V_{a}}=\frac{1-t}{1-w} \quad[25] \\
B_{p}=\frac{N\left(P_{D}\right)^{0.5}}{V_{a}^{2.5}}
\end{gathered}
$$

From Equation (16), we substitute different values of $N$ to get the corresponding value of, using the value for $\eta_{O}$ as a constant, $I$ will be able to estimate the advance coefficient $(\delta)$ and pitch to diameter $\left(\frac{P}{D}\right)$ ratio for a given blade number and blade area ratio. The following speeds from 300 - $500 \mathrm{rpm}$ were used to calculate the values for pitch diameter, shaft power etc.

The result of all the parameters calculated so far is presented with respect to the range of speed. Also, a graph of shaft power vs number of revolution is presented in Figure 3, so as to obtain the maximum possible diameter of the propeller needed for this design.

\subsection{Design Calculation}

For the chosen speed of $380 \mathrm{rpm}$,

$$
B p=\frac{380 \times(2744)^{0.5}}{(16)^{2.5}}
$$

Form the $\mathrm{Bp}-\delta$ charts $(4.55 \mathrm{~B})$

$$
\delta=198
$$

But $D=\frac{\delta \times V_{a}}{N}$

\subsubsection{Correction of Diameter}

$$
\begin{aligned}
& D=0.94 D \\
& \delta=\frac{D \times N}{V_{a}}
\end{aligned}
$$

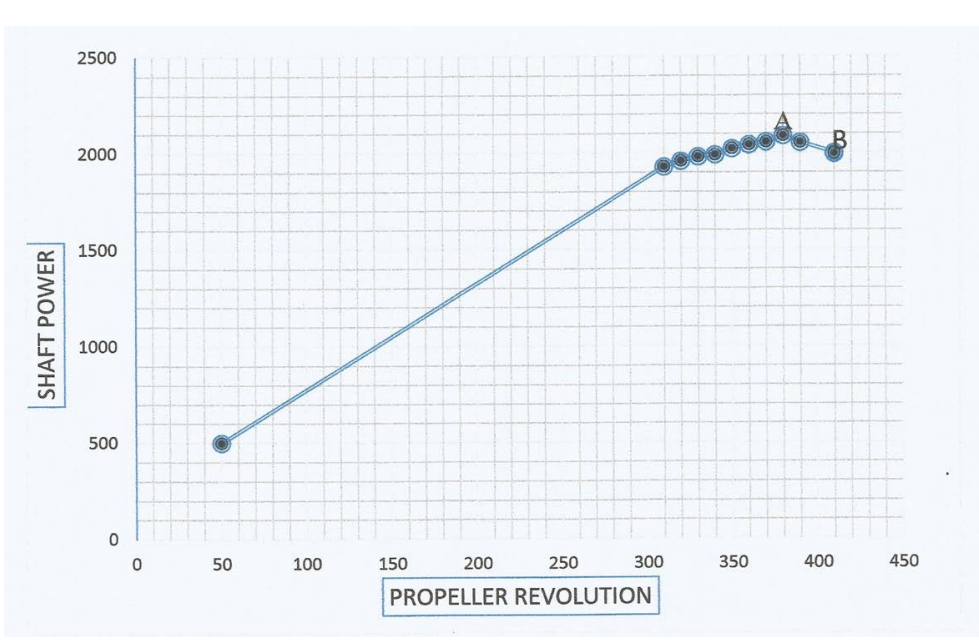

Figure 3. Graph of Shaft Power and Corresponding Propeller Rpm. 
Now using $B p=19.44$, and $\delta=186$ from the $B p-\delta$

$4.55 \mathrm{~B}$ series chart we obtain,

$$
\eta_{o}=0.59, \frac{P}{D}=0.69 \text { and } P_{D}=\frac{P_{E}}{\eta_{D}}
$$

From these parameters calculated in order to choose the correct blade area, it is necessary to apply the cavitations criterion. Table 3 shows the values for estimating cavitations criterion.

Values are gotten.

\subsubsection{Cavitation Criterion $(\sigma)$}

$$
\begin{gathered}
\sigma=(0.7 R)=P_{O}-P_{V}=\frac{1}{2} P \times(V 0.7 R)^{2} \quad[26] \\
\text { But } P_{O}-P_{V}=14.45+0.45 h
\end{gathered}
$$

From simple cavitation diagrams, the value of $T_{C}$ corresponding to 0.24146 is 0.10 .

$$
\begin{gathered}
\therefore T_{C}=0.10 \\
\Rightarrow \frac{\frac{T}{A p(p s l)}}{\frac{1}{2} \times l \times V_{R}^{2}}=\frac{T}{A p}=T_{C} \times \frac{1}{2} \times l \times V_{R}^{2}
\end{gathered}
$$

\subsubsection{Estimating the Thrust of the Tug}

$$
\begin{gathered}
R_{T}=(1-t) \times T \quad[24] \\
\Rightarrow T=\frac{R_{T}}{1-t} \\
\text { But } \frac{T}{A p}=6.4976 \\
\text { The disk area } A_{o}=\frac{\pi D^{2}}{4} \\
\Rightarrow A_{D}=\frac{A_{P}}{0.90899} \\
\text { Hence, } \frac{A_{P}}{A_{D}}=\frac{37937.7}{41736}=0.91
\end{gathered}
$$

\subsection{Calculation of Normal Propeller Curve}

To obtain the propeller curve, the power-speed relationship of the propeller will be used, which is also referred to as the propeller law.

Table 3. Values for estimating cavitations criterion [10].

\begin{tabular}{cccc}
\hline Blade area ratio & 0.40 & $\mathbf{0 . 5 5}$ & $\mathbf{0 . 7 0}$ \\
\hline Pitch ratio & 0.98 & 1.0 & 0.99 \\
Efficiency & 0.58 & 0.57 & 0.60 \\
\hline
\end{tabular}




$$
P=k n^{3}
$$

In order to linearize the above equation so as to make it easy for calculations, we take $\log$ of both sides of the equations,

$$
\begin{gathered}
\Rightarrow \log P=\log k n^{3} \\
\therefore \log P=\log k+3 \log n
\end{gathered}
$$

$k$ can be determined by using the already calculated values for shaft power $\left(P_{S}\right)$ and speed $(n)$ already obtained;

Hence, $\log P=\log k+3 \log n$

Making $\mathrm{k}$ the subject of the equation $\log k=\log P-3 \log n$.

\subsection{Calculation of Nominal Main Engine Curve}

To obtain the main engine curve the power speed relationship of brake power is used and it is known as the main engine curve characteristics and is given below,

$$
P=T \times \omega \quad[22]
$$

where $P=$ brake power, $T=$ thrust and $\omega=$ angular speed $=2 \pi n$

But from the propeller curve characteristics where the equilibrium position occurs, the power of the propeller equals power of the main engine at that speed. Therefore, $P=T \times \omega=P=k n^{3}$

\section{Discussion of Results and Findings}

The construction of the propulsion system for water borne craft requires estimating the hull resistance of the craft first, so as to enable us design an effective vessel with low resistance and maximize efficiency. In this design, we estimated the tug resistance $\left(R_{T}\right)$, which accounted for the total resistance of the tug in operation, and the effective power $\left(P_{E}\right)$ needed to overcome this resistance was evaluated.

Figure 3 indicates that the power supplied by the main engine is effectively put to use at (A) as this is the highest point of the graph. At point $A$ the main engine will supply a power of $2088 \mathrm{KW}(2799 \mathrm{hp})$ to effectively overcome the tug resistance and propel the ship forward, at a speed of $380 \mathrm{rpm}$. It is evident from the graph that from point 0 to $\mathrm{A}$ shows a corresponding increase in propeller rpm as the shaft power increase, but from point A to B shows a clear pattern of increase in propeller rpm even as the shaft power gradually decreases. Hence it can be deduced that for maximum efficiency and optimum system performance, the shaft power should be $2088 \mathrm{KW}$ at a propeller rpm of 380 and having a diameter of $7.24 \mathrm{ft}(2.2 \mathrm{~m})$ as shown in Table 4.

In matching procedures, one needs to make sure that the propeller so designed is to absorb all the delivered power from the prime mover. If we over look this important condition and the propeller is overloaded, then cavitations must likely occur, which shortens the life span of the propeller and cause wear and excessive vibration of the propulsion system. To prevent this from occurring, a 
Table 4. Values for shaft power and corresponding propeller rpm.

$\begin{array}{llllllllllllllllll}\text { RPM } & 300 & 310 & 320 & 330 & 340 & 350 & 360 & 370 & 380 & 390 & 400 & 410 & 420 & 430 & 440 & 450 & 460\end{array}$

$P_{s} \quad 18961927195719801990202220422056208820532000199419881957197922072167$

reduction gear is used so that at any point in time the propeller is not over loaded. Also during matching, there must be power equality between the main engine and propeller for optimum propulsive efficiency. The matching must be done in such a way that engine power is equal to propeller power $\left(P_{I}=P_{D}\right)$.

Equilibrium of operations is based on

1) Speed balance: This requires that the propeller speed must be equal to engine speed, by using a reduction gear for high speed engines. Hence, rotational speed of engine is equal to rotational speed of propeller multiplied by the gear ratio $\left(N_{1}=N_{2} \times I\right)$.

2) Torque balance: Requiring that the torque necessary to rotate the propeller must be delivered into the shaft line. i.e. power $=$ torque $\times$ angular speed $(P=T \times \omega)$.

3) Power compatibility: This requires that power generated by engine is equals power utilized by propeller plus power losses in the shaft line bearing. In practice, the propeller and the engine layout diagram are the basic tools of matching analysis.

The engine selected must be able to operate the propeller when loaded and when unloaded. In achieving this, the propeller law was used and values are shown in Table 5.

Figure 4 clearly shows the relationship between the engine and the propeller. The point $\mathrm{C}$ is where the straight line and the curve meet, this point is called the matching point, this is the point where all the power produced by the engine is effectively been absorbed by the propeller. In this design the suitable propeller rpm is $380 \mathrm{rpm}$ with engine power of $2837 \mathrm{kw}$ and a propeller power of $2088 \mathrm{kw}$. In matching propeller to engine, we use the plots obtained for various propeller at maximum speed and try to match it to the different engine power from test bed. For a propeller to rotate at $N_{1}$, it will require a power $P_{1}$ and to maintain the engine at $N_{2}$ we require a power of $P_{2}$, it means that the higher the engine speed the higher the power produced. When an engine is operating beyond the maximum continuous rating (MCR) for more than 5 mins the engine trips off. In practice however, the propeller/engine curve is converted into a linear graph byintroducing log to the power from the propeller law as shown in Equation (26) and (27).

Figure 5, show the engine-propeller curve characteristics at different sea state (note: A indicates the Propeller not in water curve, B shows the Propeller in calm water (weather) curve and $\mathrm{C}$ is the Propeller in rough water curve). The plot indicates that the power delivered increase because of increase load due to rough sea state with a progressive increase in the propeller speed. Displacement of propeller curves caused by bad weather increases the resistance of the tugs 
Table 5. Rotational speed to brake power and shaft power.

\begin{tabular}{ccccccccccccc}
\hline$N$ & 300 & 310 & 320 & 330 & 340 & 350 & 360 & 370 & 380 & 390 & 400 & 410 \\
\hline $3 \log N$ & 7.431 & 7.474 & 7.515 & 7.555 & 7.594 & 7.6322 & 7.6689 & 7.7046 & 7.7394 & 7.7730 & 7.8062 & 7.838 \\
$\log N$ & 2.477 & 2.491 & 2.505 & 2.519 & 2.544 & 2.5563 & 2.5682 & 2.5798 & 2.2 .579 & 2.5110 & 2.6020 & 2.612 \\
$\log K$ & -4.31 & -4.31 & -4.32 & -4.32 & 4.318 & -4.318 & -4.318 & -4.318 & -4.318 & -4.318 & -4.318 & -4.32 \\
$\log P$ & 3.113 & 3.156 & 3.197 & 3.238 & 3.276 & 3.31428 & 3.3508 & 3.380 & 3.3421 & 3.4554 & 3.4881 & 3.520 \\
$P_{в}(\mathrm{~kW})$ & 1396 & 1541 & 1695 & 1858 & 1889 & 2062 & 2243 & 2433 & 2638 & 2850 & 3077 & 3313 \\
$P_{S}(\mathrm{~kW})$ & 1896 & 1927 & 1957 & 1980 & 1990 & 2022 & 2042 & 2056 & 2088 & 2053 & 2000 & 1994 \\
\hline
\end{tabular}

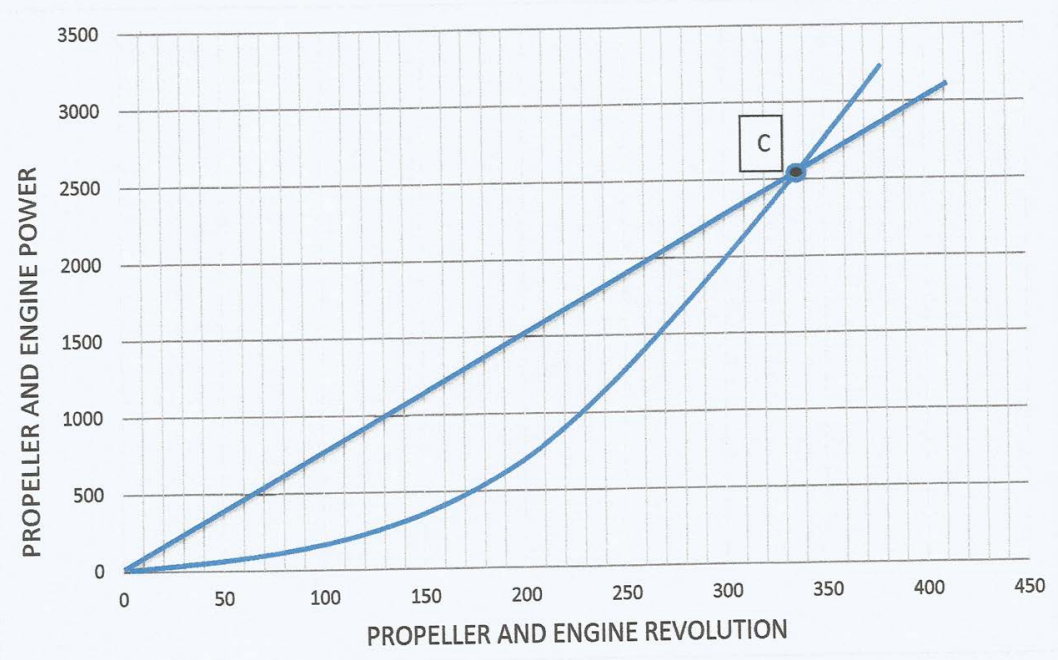

Figure 4. Graph of engine-propeller matching.

movement, fouling is also a factor that increases the resistance of the tug hull. Normally when estimating the necessary propeller power and speed, we use theoretical calculations for loaded ship and often experimental tank tests, both assuming optimum operating conditions, i.e. clean hull and good weather. The combination of speed and power obtained is mostly referred to as propeller design point PD as shown by the curves on the graph below. Figure 6 show the propeller curve at three different engine rating (note: $\mathrm{A}$ indicates the Normal Continuous rating, $\mathrm{B}$ shows the Maximum Intermittent rating while $\mathrm{C}$ is the Maximum Continuous rating). The plot indicates a progressive increase in the $\mathrm{rpm}$ to a point of maximum rpm, then decrease gradually. This gives a guide on the propeller loading even at different operating state of the engine.

\section{Conclusions}

This work is to effectively and meticulously design the propulsion system of a twin-screw tugboat. The process for achieving this involves the effective matching and selection of the main engine and the propeller while putting into consideration the dimension of the tug boat.

The prime mover selected for this design will drive a fixed pitch propeller whose diameter and geometry was also designed for this purpose, via a reduction 


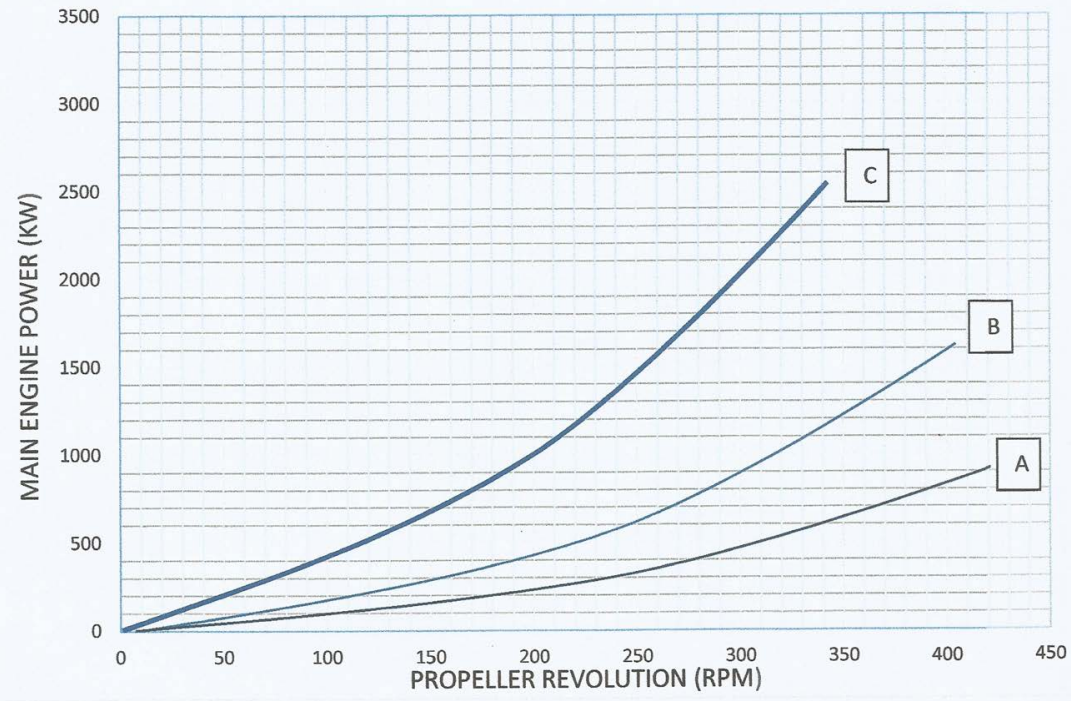

Figure 5. Graph of main engine and propeller at different sea state.

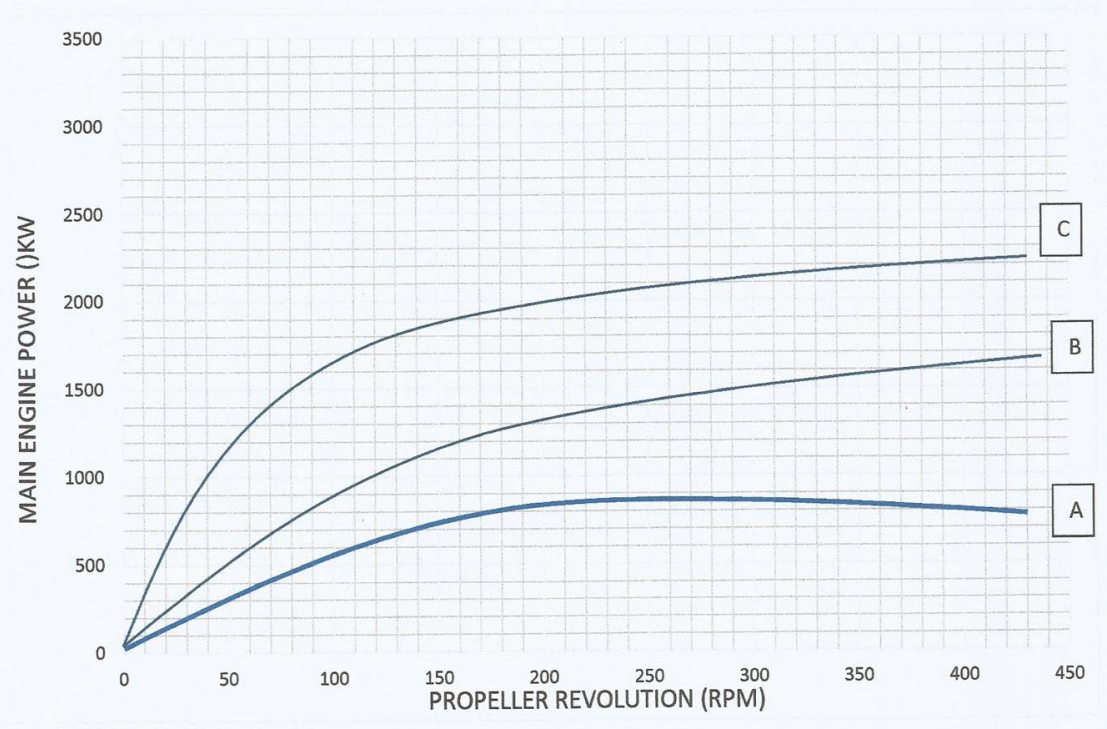

Figure 6. Different engine curve characteristics.

gear box and shafting, rotating in a well lubricated bearing. In this design work provision has also been made so as to reduce vibration noise and loss in energy by designing the propeller in such a way that it can effectively absorb all the power generated by the prime mover. The performance of must vessels and tugs is dependent on the design and construction of the tug. Hence, for effective performance and the guarantee of the life span of this tug, the calculated parameters for the propeller, main engine dimension and hull resistance estimation, power distribution calculations and the choice of the main engine must be adhered to during construction. Most of the accidents that occur on our water ways due to tugboat and engine failures are mostly as a result of greed and negligence on the 
part of tugboat owners. It is expected that this twin screw tugboat has 24 days maximum endurance, service speed of $16 \mathrm{knots}$, and a total number of $10 \mathrm{crew}$ members but most times we see boat owners trying to overcrowd the boats.

\section{References}

[1] Nordtun, T. (2009) Electric Propulsion System s for Offshore Support Vessels. Wartsila.

[2] Herdzik, J. (2010) Problems of Propulsion Arrangement Choice of Multi-Mode Vessels. Journal of Kones, 17, 12-19.

[3] Minsaas, K. and Steen, S. (2008) Propeller Theory. Sit Tapir, Trondheim.

[4] Nitonye, S. (2017) Design Calculations for Equipment and Components Specification for Lubricating oil System of a Tug Boat. International Journal of Advances in Engineering and Technology, 10, 449-462. http://www.ijaet.org/

[5] Phani Krishna, A.H. (2013) Tug Boats Propulsion. www.navalarch.weebly.com/near-coastal-vessels/tug-boats-propulsion

[6] Machinery Spaces (2015) Ship Propeller Shaft-Thrust Blocks and Shaft Bearings. http://www.machineryspaces.com/cooling.html

[7] Smith, E.C. (1905) A Short History of Naval and Marine Engineering. University Press, Cambridge.

[8] Lewis, V. and Edward, Ed. (1989) Principle of Naval Architecture, Society of Naval Architects and Marine Engineers.

[9] Pike, J. and Sherman, R. (1999) US Navy Propulsion Systems. http://www.fas.org/man/dod-101/sys/ship/eng/

[10] Martinez, I. (1995) Marine Propulsion, "Selecting an Efficient Propulsion System". Isodiro Martinez Enterprise.

[11] Nielsen, J.R. and Marinussen, H. (2010) Optimising Propulsion Systems for AHTS Vessels. Ship \& Offshore, 2, 10-13.

[12] Sciberras, E.A. and Norman, R.A. (2012) Multi-Objective of a Hybrid Propulsion System for Marine Vessels. IET Electrical Systems in Transportation, 2, 148-157. https://doi.org/10.1049/iet-est.2011.0011

[13] Øyan, E. and Steen, S. (2012) Speed and Powering Prediction for Ships Based on Model Testing. Department of Marine Technology, Norwegian University of Science and Technology.

[14] Balu, S. (2011) Modern Electrical Propulsion Systems for LNG Tankers (Unpublished).

[15] Samson, N. (2017) Numerical Analysis for the Design of the Fuel System of a Sea Going Tug Boat in the Niger Delta. World Journal of Engineering Research and Technology, 3, 161-177. http://www.wjert.org

[16] Lloyd's Register of Shipping (1976) Lloyd's Rules and Regulations for the Construction and Classification of Steel Ships. Lloyd's Publisher.

[17] Samson, N. (2015) Stress and Resistance Analysis for the Design of a Work Barge, International Journal of Scientific and Engineering Research, (IJSER) India, 6, 1064974. http://www.ijser.org

[18] Nitonye, S., Ogbonnaya, E.A. and Ejabefio, K. (2013) Stability Analysis for the Design of 5000-Tonnes Offshore Work Barge. International Journal of Engineering and Technology, 3, 849-857. http://www.ijet.journal.org 
[19] Diesel Electric Drives, MAN, 2010.

[20] A Supplement to International Tug or OSV, Cummins, USA 2012.

[21] The Development of Ulstein Hybrid Propulsion Concept and Installation on Olympic Zeus and Olympic Hera Ulstein 2009.

[22] Samson, N. and Adumene, S. (2015) Comparative Modeling of Hull Form Resistance for Three Ocean Going Vessels Using Methodical Series. International Journal of Engineering and Technology, (IJET) Germany, 4, 489-496.

http://www.sciencepubco/index.php/IJET.com https://doi.org/10.14419/ijet.v4i4.4948

[23] Dimensions Info because Size Matters (2015) Tug Boat Dimension. www.dimensioninfo.com/tug-boat-sizes

[24] Krishnankutty, P. (2015) Ship Resistance and Propulsion. Indian Institute of Technology, Madras.

[25] Bose, N., Billet, M., Andersen, P., Atlar, M., Duge, C., Ferrando, M., Qian, W. and Shen, Y. (1999) Final Report and Recommendations to the 22nd ITTC from the Specialist Committee on Unconventional Propulsors. Proceedings from the $22 \mathrm{nd}$ ITTC.

[26] Lindgren, H., Aucher, M., Bowden, B., Gross, A., Minsaas, K., Muntjewerf, J., Tamura, K. and Wermter, R. (1978) Report of Performance Committee. 15th ITTC Proceedings, 15th International Towing Tank Conference in the Hauge, The Netherlands.

[27] Minsk, M.P. (2013) Diesel Engines Operation Manuals, Minsk Motor Company, Plant Holding. 


\section{Nomenclature}

$A_{E}$ : Expanded area (of the propeller blade)

$A_{M}$ : Midship area

$A_{O}$ : Area of propeller disc

$A_{P}$ : Projected area (of the propeller blade)

$B_{P}$ : Taylor's propeller coefficient

$C_{A}$ : Correlation Allowance

$C_{B}$ : Block coefficient

$C_{F}$ : Friction resistance coefficient

$C_{M}$ : Midship coefficient

$C_{R}$ : Residual resistance coefficient

$C_{T}$ : Coefficient of total hull resistance in calm water

$C_{W L}$ : Wave resistance coefficient

$D$ : Propeller Diameter

$g$ : Acceleration due to gravity

$K$ : Propeller constant

$L_{P P}$ Length Perpendicular

$M_{B}$ : Brake torque

$M_{S}$ : Shift torque

$N$ : Revolutions

$P_{B}$ : Brake power

$P_{D}$ : Delivered power

$P_{E}$ : Effective power

$P_{I}$ : Indicated power

$P_{S}$ : Shaft power

$P_{T}$ : Thrust power

$Q$ : Propeller torque

$Q_{O}$ : Propeller torque in open water

$R_{T}$ : Total ship resistance

$S_{w}$ : Wetted Surface Area

$T$ : Thrust deduction fraction

$V_{A}$ : Speed of advance

$V_{S}$ : Ship speed

$B_{M}$ : Moulded breath

$\rho_{w}$ : Density of water

$\eta_{G}$ : Efficiency of gear

$\eta_{H}:$ Hull efficiency

$\eta_{o}$ : Open water efficiency

$\eta_{s}$ : Shaft efficiency 


\section{Appendix}

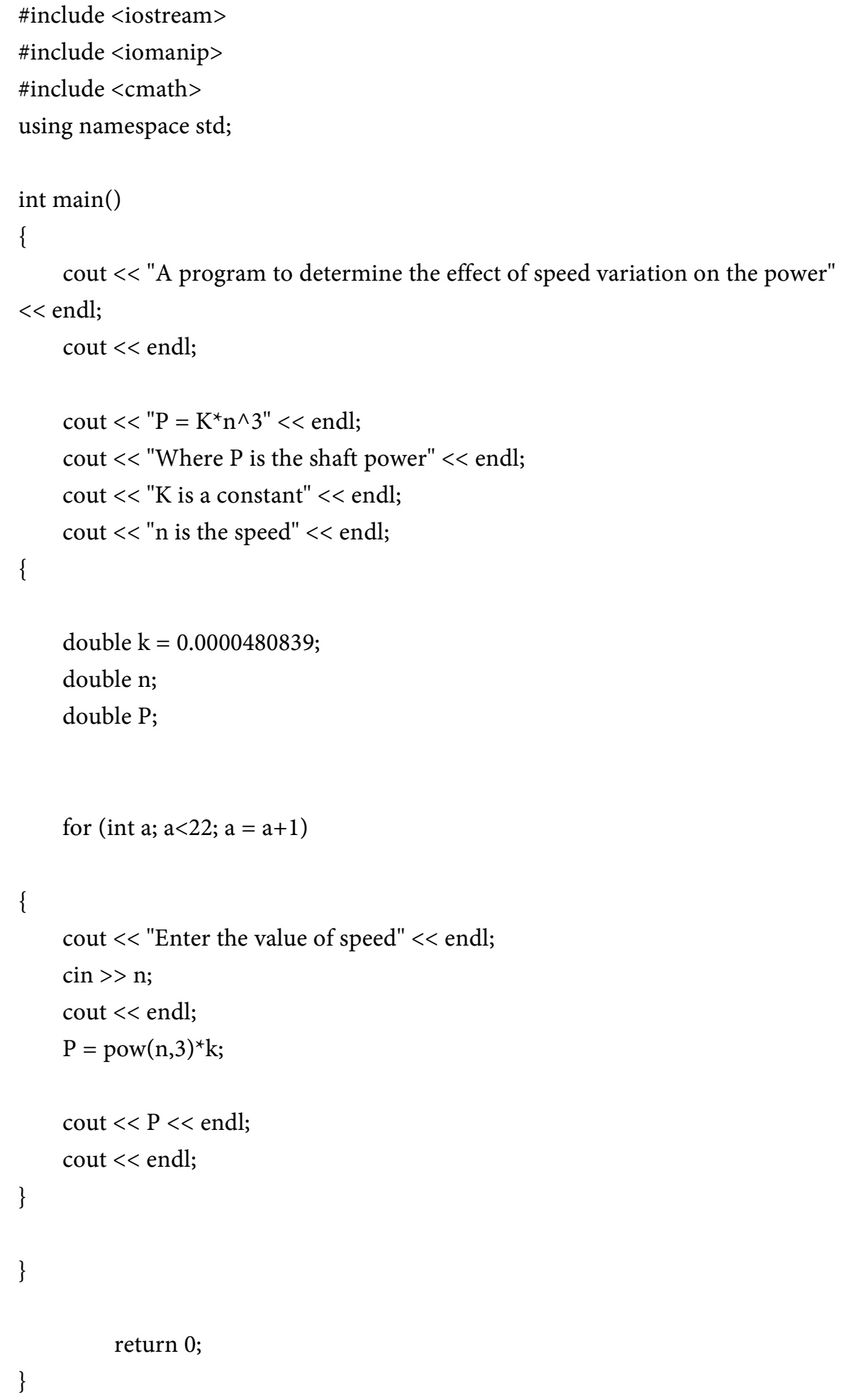




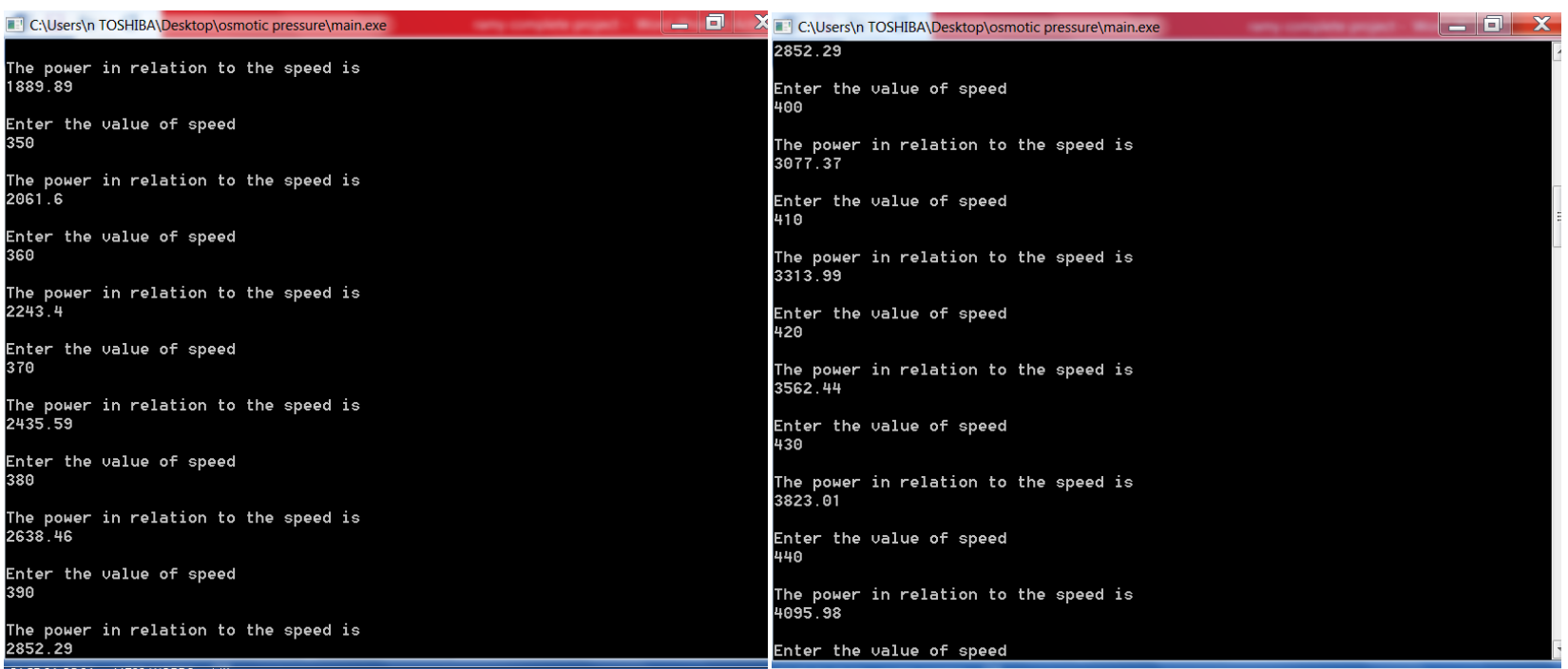

T. C:Users\n TOSHIBA|Desktoplosmotic pressurelmain.exe Enter

The power in relation to the speed is 4381.65

Enter the value of speed

460

The power in relation to the speed is 4680.29

Enter the value of speed

470

The power in relation to the speed is 4992.21

Enter the value of speed

480

The power in relation to the speed is 5317.69

Enter the value of speed

490

The power in relation to the speed is 5657.02

Enter the value of speed

500

A C:Users $\backslash n$ TOSHIBAIDesktoplosmotic pressurelmain.
$P=K * n n^{3}$
Where $P$ is the shaft power
$K$ is a constant
$n$ is the speed
Enter the value of speed
300
The power in relation to the speed is

The power
1298.27

Enter the value of speed

310

The power in relation to the speed is

1432.47

Enter the value of speed

320

The power in relation to the speed is

1575.61

Enter the value of speed

330

The power in relation to the speed is

1727.99

Enter the value of speed

340

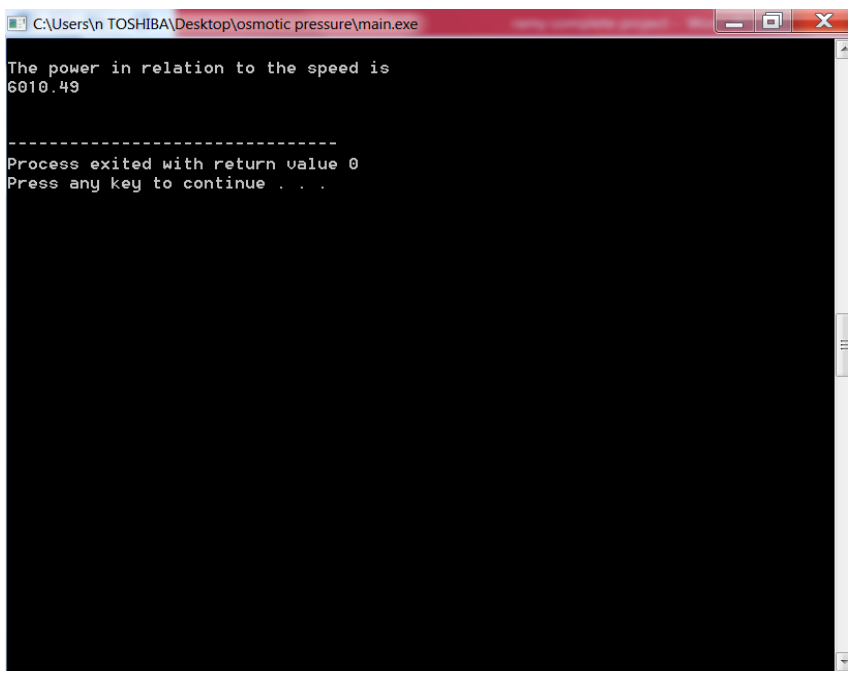

